\title{
SORPTION OF RADIOIODINE ON ORGANIC RICH SOIL, CLAY MINERALS AND ALUMINA
}

\author{
S. ASSEMI, H. N. ERTEN \\ Bilkent University, Chemistry Department, 06533 Ankara (Turkey)
}

(Received August 31, 1993)

\begin{abstract}
Batch method was used to investigate the sorption behavior of radioiodine on organic rich soil, alumina, chlorite-illite clay mixture and bentonite. ${ }^{131}$ I was used as tracer. The grain sizes of the samples used were all below $38 \mu \mathrm{m}$. A rather slow kinetics was observed for the adsorption of radioiodine on organic rich soil. The distribution ratio increased with increasing solution/solid $(\mathrm{V} / \mathrm{m})$ ratio, and the contact time. The $\mathrm{pH}$ of the synthetic groundwater did not change the distribution ratio appreciably. The soil biomass however, showed a striking effect on the adsorption of radioiodine. Among the clay minerals, the highest distribution ratio value was found for chlorite-illite clay mixture. All the values were however well below those of the organic rich soil. The sorption data were fitted to Freundlich and Dubinin-Radushkevich type isotherms. Mean energies of adsorption, as well as the affinity ratios of the sorption sites to iodine and chlorine were calculated.
\end{abstract}

The use of radionuclides in nuclear power plants, their medical, agricultural, industrial and scientific applications in ever increasing quantities, leads to the problem of radioactive wastes. This is potentially harmful to both man and his environment. The wastes range in activity from near natural background as those used in radio-medicine, to very high activities from nuclear reactor fuels. ${ }^{1}$

Different conceptual methods for the disposal of radioactive wastes have been proposed. ${ }^{2}$ Among them, underground disposal seems to be the most preferred way, because of both economical and technological points of view. Although the access of water to the emplaced waste and transport from a repository are not likely in most cases, a long-term safety program should model conceivable scenarios in which this access and transport by water could nevertheless occur. This makes the properties of the backfills, clays and soils, the groundwater and the chemical nature of the radionuclides to be disposed, important parameters to be studied.

Iodine has two important isotopes with respect to radioactive wastes. ${ }^{129} \mathrm{I}$ with a half-life of $1.57 \cdot 10^{7} \mathrm{y}$ and ${ }^{131} \mathrm{I}$ with a half-life of $8.04 \mathrm{~d}$. The long half-life of ${ }^{129} \mathrm{I}$ and the high specific activity of ${ }^{131} \mathrm{I}\left(1.23 \cdot 10^{4} \mathrm{Ci} / \mathrm{g}\right)$ make them both important contaminants of the environment in the long and short terms, respectively. They are produced during the operation of nuclear power plants, the reprocessing of nuclear fuel and testing of nuclear weapons. ${ }^{3}$ Iodine can be easily transported in the environment because of its volatility. In concentrates in the thyroid gland and in other tissues in human beings. 


\section{Materials and methods}

The solid samples used were an organic rich soil from Bolu-Yeniçağ region in Turkey with a high percentage of organics $\left(C_{\text {org }} \cong 70 \%\right.$ ), alumina, kaolinite, bentonite and chlorite-illite clay mixture. The organic rich soil was obtained from the Agricultural Faculty of Ankara University. Alumina and clay minerals were obtained from Mineral

Table 1

Composition of the synthetic groundwater used in sorption studies

\begin{tabular}{lc}
\hline Ion & $\begin{array}{c}\text { Concentration, } \\
\text { meq/ }\end{array}$ \\
\hline $\mathrm{Na}^{+}$ & 2.17 \\
$\mathrm{Ca}^{2+}$ & 3.90 \\
$\mathrm{Mg}^{2+}$ & 3.10 \\
$\mathrm{CO}_{3}^{2-}$ & - \\
$\mathrm{HCO}_{3}^{-}$ & 7.06 \\
$\mathrm{Cl}^{-}$ & 0.60 \\
$\mathrm{SO}_{4}^{2-}$ & 1.75 \\
$\mathrm{~K}^{+}$ & 0.24 \\
\hline
\end{tabular}

Institute (M.T.A.) in Ankara. The samples were separated into different particle sizes by dry sieving and the fraction below $38 \mu \mathrm{m}$ was used in the experiments. To approximate natural conditions, synthetic groundwater was used which simulated the composition of the groundwaters of the regions where the solid samples were taken. The composition of the groundwater used in the sorption experiments is given in Table 1. The iodine tracer used was ${ }^{131} \mathrm{I}(8.04 \mathrm{~d})$ in the form of $\mathrm{NaI}$ salt. The initial $\mathrm{I}^{-}$anion concentration in the solutions ranged from $1.0 \cdot 10^{-3}$ to $1.0 \cdot 10^{-8} \mathrm{mmol} / \mathrm{ml}$.

All sorption experiments were performed using the batch method. Weighed amounts of duplicate samples were suspended in polypropylene centrifuge tubes in known volumes of tracer containing solutions. The tubes were shaken at room temperature on a lateral shaker. The two phases were separated by centrifuging at $12,000 \mathrm{rpm}$ for 30 minutes. The change in activity of the supernatant was determined, using a NaI detector. The distribution ratio $R_{d}$ was calculated using the following relation: ${ }^{4}$

$$
R_{d, a d}=\frac{V \cdot A_{0}-A_{1, a d}\left(V+\Delta W_{p t}\right)}{W_{s} \cdot A_{1, a d}}
$$


where $\quad R_{a, a d}-$ adsorption distribution ratio $(\mathrm{ml} / \mathrm{g})$,

$A_{0}$ - initial activity of the solution (cpm/ml),

$A_{1 \text { ad }}$ - activity of the solution after sorption (cpm/ $\left.\mathrm{ml}\right)$,

$V$ - volume of the liquid phase $(\mathrm{ml})$,

$\Delta W_{p t}$ - weight of the solution remaining in the solid phase after pretreatment $(\mathrm{g})$,

$W_{s}$ weight of the solid phase (g).

For the desorption experiments, the two phases were separated following the adsorption step and four milliliters of synthetic groundwater was added to the sample tube and shaken. The phases were again separated by centrifuging and the activity of the supernatant was counted. $R_{d, \text { des }}$ was calculated according to the relation:

$$
R_{d, \text { des }}=\frac{V\left(A_{0}\right)-V\left(A_{1, a d}+\Delta W_{a d}\right)}{W_{s} \cdot A_{1, \text { des }}}
$$

where: $R_{d, \text { des }}$ - desorption distribution ratio $(\mathrm{ml} / \mathrm{g})$,

$\Delta W_{a d}$ - amount of liquid remaining in the centrifuge tube after adsorption (g).

Adsorption, desorption, sorption reversibility and isotope exchange percentages were calculated using the following relations:

$$
\begin{gathered}
\text { Adsorption } \%=\left(\frac{V A_{0}-A_{1, a d}\left(V+\Delta W_{p t}\right)}{V A_{0}}\right) \cdot 100 \\
\text { Desorption } \%=\left(\frac{A_{1, d e}\left(V+\Delta W_{a d}\right)-A_{1, a d} \cdot \Delta W_{p t}}{V A_{0}-A_{1, a d}\left(V+\Delta W_{p t}\right)}\right) \cdot 100 \\
\text { Exchange } \%=\left(\frac{V A_{0}-A_{1, \mathrm{ex}}\left(V+\Delta W_{p t}\right)}{V A_{0}}\right) \cdot 100 \\
\text { Reversibility } \%=\left(\frac{\% \text { Des }}{100-\% \text { Ads }}\right) \cdot 100
\end{gathered}
$$

\section{Results and discussion}

The variation of the distribution ratio with time for organic rich soil was studied using an initial iodine concentration, $\left[\mathrm{I}^{-}\right]_{l}^{0}$ of $1 \cdot 10^{-6} \mathrm{M}$ at room temperature. The results are shown in Fig. 1. Sorption was rather slow and tended towards saturation in about 


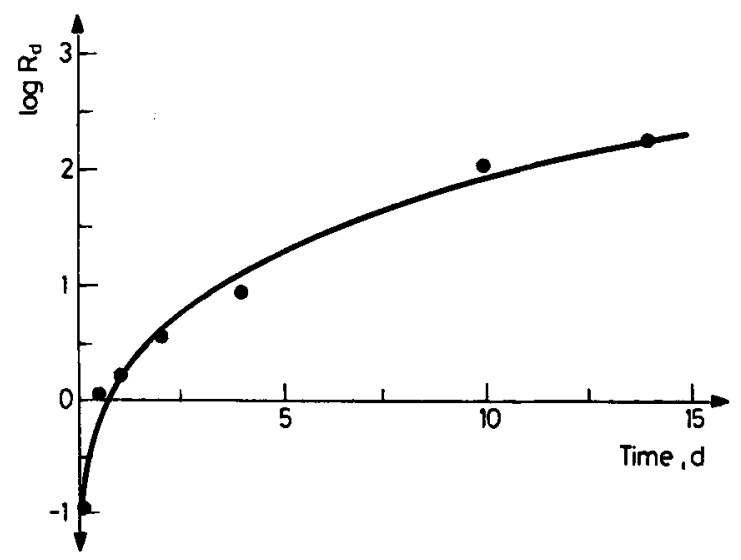

Fig. 1. Variation of the distribution ratio $R_{d}$ with time for organic rich soil. Initial iodine concentration: $\left[\mathrm{I}^{-}\right]_{l}^{0}=1 \cdot 10^{-6} \mathrm{mmol} \cdot \mathrm{ml}^{-1}$

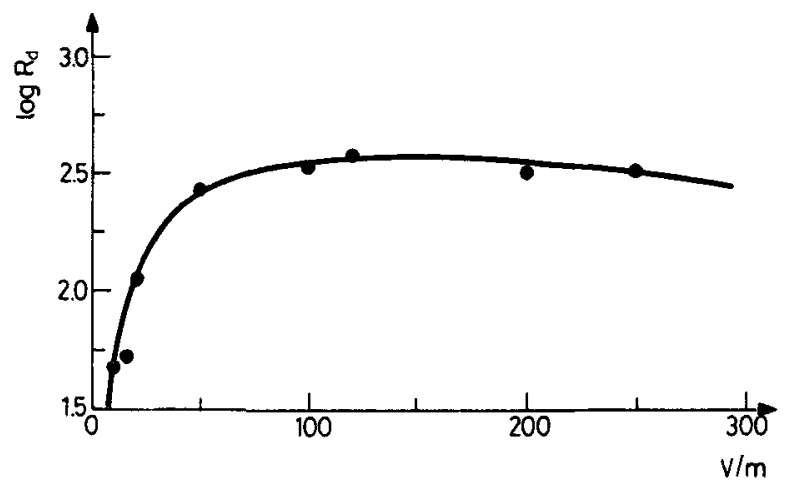

Fig. 2. Variation of the distribution ratio $R_{d}$ with the volume of solution to mass of soil ratio $(\mathrm{V} / \mathrm{m})$. Initial iodine concentration: $\left[\mathrm{I}^{-}\right]_{l}^{0}=1 \cdot 10^{-6} \mathrm{mmol} \cdot \mathrm{ml}^{-1}$

14 days. This long time may be due to the complex and heterogeneous structure of the soil. Increasing the organic part of the soil leads to an increase in the saturation time. ${ }^{5}$

The effect of $\mathrm{V} / \mathrm{m}$ (the ratio of volume of tracer containing solution to that of the mass of sorbent) was studied using an initial iodide concentration $\left[\mathrm{I}^{-}\right]_{1}^{0}$ of $1 \cdot 10^{-6} \mathrm{M}$ at room temperature. The results are shown in Fig. 2. An initial strong dependence of the distribution ratio $R_{d}$, on $V / m$ is observed up to $V / m \equiv 50$, whereafter a plateau region is reached. Increasing the volume to mass ratio, results in better dispersion of the soil particles and their organic components in the soil, as a result the inner surfaces become 
more exposed. When all of the available sorption sites are covered with iodine, increasing the $V / m$ ratio further, does not change the $R_{d}$ appreciably.

The $\mathrm{pH}$ dependence of the distribution ratio for the adsorption of radioiodine on Bolu-Yeniçag Soil is shown in Fig. 3. It is seen that the distribution ratio fluctuates below $\mathrm{pH} 7$. Above that $\mathrm{pH}$, the changes are not significant. According to the Eh-pH

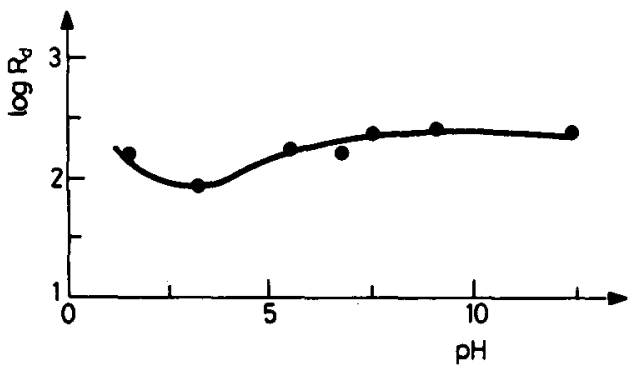

Fig. 3. Variation of the distribution ratio $R_{d}$ with $\mathrm{pH}$ of the solution. Initial iodine concentration: $\left[\mathrm{I}^{-}\right]_{l}^{0}=1 \cdot 10^{-8} \mathrm{mmol} \cdot \mathrm{ml}^{-1}$

diagram of iodine-water system, iodide ion is stable over a wide range of Eh and $\mathrm{pH} .{ }^{6,7}$ Other iodine species were not determined in this study. The Eh of the synthetic groundwater was measured as $0.047 \mathrm{~V}$, which corresponds to the $\mathrm{I}^{-}$region. The Eh was measured for a $\mathrm{pH}$ range of 1 to 12 for a solution with $\left[\mathrm{I}_{i}^{0}=1 \cdot 10^{-8} \mathrm{M}\right.$. The values observed were in the range of 0.3 to $-0.3 \mathrm{~V}$. In this range iodine is expected to be mostly in $\mathrm{I}^{-}$form in the solution. Similar observations of $\mathrm{pH}$ dependence of sorption are reported by SHEPPARD and THAIBAULT. ${ }^{8}$

The microorganisms are known to be very effective in iodine sorption. ${ }^{5,9}$ To study this effect, the soil samples were sterilized by heat $\left(180{ }^{\circ} \mathrm{C}\right.$ for 2 hours) and by $\gamma$-irradiation, using a ${ }^{60} \mathrm{Co}$ source and a dose of $2.7 \cdot 10^{6} \mathrm{rad}$. This $\gamma$-dose seems to be enough to inactivate the microbial part and is comparable with the values given in the literature which are about $10^{2}$ to $10^{5} \mathrm{rad}^{10}$. Sorption experiments were performed immediately following irradiation using the sterilized soil and a control sample. The results are given in Table 2.

The difference between the $R_{d}$ values of sterilized and non-sterilized samples are quite striking. The results indicate the strong influence of microorganisms in the sorption of iodine. The soil samples sterilized with a ${ }^{60} \mathrm{Co} \gamma$-source, have somewhat higher $R_{d}$ values compared to those sterilized by heat. The reason may be due to the structural changes in soil brought about by heating. Cleavage of some bonds by the $\gamma$-radiation may also affect the adsorption. BORS et al., ${ }^{5}$ have also reported the decrease 
Table 2

Effect of sterilization on the sorption of iodine on organic rich soil

\begin{tabular}{lc}
\hline \multicolumn{1}{c}{ Soil sample } & $\begin{array}{c}\text { Distribution ratio } \\
\left(R_{d}\right), \mathrm{ml} / \mathrm{g}\end{array}$ \\
\hline Soil sterilized by heat $\left(180^{\circ} \mathrm{C}\right)$ & 8.3 \\
Soil sterilized by ${ }^{60} \mathrm{Co}$ radiation & \\
$\quad\left(2.7 \cdot 10^{6}\right.$ rads $)$ & 26.5 \\
Control soil & 138.2 \\
\hline
\end{tabular}

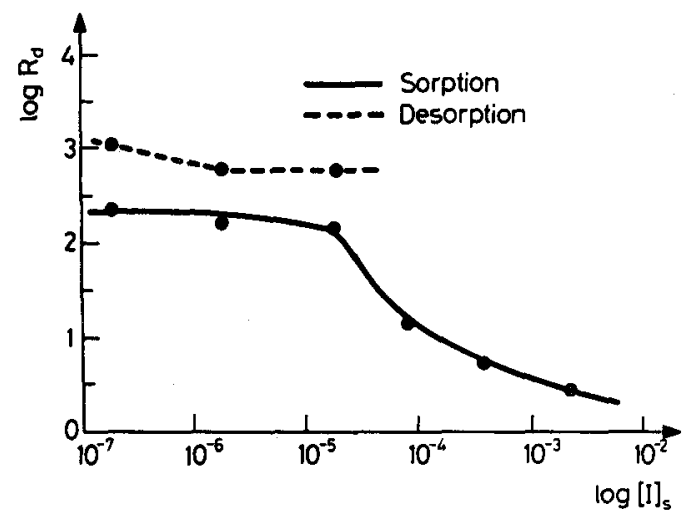

Fig. 4. Variation of the distribution ratio $R_{d}$ with $\mathrm{I}^{-}$ion concentration on a solid matrix for organic rich soil

of $R_{d}$ values, when soil was sterilized by heat or $\mathrm{CH}_{3} \mathrm{Cl}$ fumigation. STRACK and MILTON have similarly reported that autoclaving reduced the immobilization of iodine. ${ }^{11}$

The effect of initial $\mathrm{I}^{-}$ion concentration in solution on the sorption of radioiodine by soil is shown in Fig. 4. It was observed that the distribution ratio decreases with increasing initial iodine concentration. A somewhat constant $R_{d}$ region is observed in the loading curve for $\left[\Pi_{s} \leq 5 \cdot 10^{-5} \mathrm{mmol} / \mathrm{g}\right.$ and beyond that point, a gradual decrease in $R_{d}$ values is observed. Desorption was observed only in the constant $R_{d}$ region. Desorption from the high $R_{d}$ region suggests that adsorption mechanism involves more than one layer. The loosely bound ions in the exterior layers are the ones that are desorbed. The corresponding loading curve for clay minerals is shown in Fig. 5. Chlorite-illite clay shows similar behavior as the soil, whereas bentonite, kaolinite and alumina all show low adsorption for iodine. 
Table 3

Adsorption, desorption, reversible sorption and exchange percentages for adsorption of radioiodine on organic rich soil, calculated from the adsorption, desorption and exchange distribution ratios

\begin{tabular}{cccccc}
\hline$\left[I_{l}, \mathrm{mmole} / \mathrm{ml}\right.$ & $A, \%$ & $D, \%$ & $R, \%$ & $E, \%$ & $R_{\text {der }} \mathrm{ml} / \mathrm{g}$ \\
\hline $1 \cdot 10^{-3}$ & 11.0 & 0 & 0 & 0 & 0 \\
$1 \cdot 10^{-4}$ & 19.2 & 0 & 0 & 9.7 & $2.2 \pm 0.97$ \\
$1 \cdot 10^{-5}$ & 39.4 & 0 & 0 & 5.5 & $1.2 \pm 0.78$ \\
$1 \cdot 10^{-6}$ & 87.4 & 1.5 & 12.3 & 2.3 & $7.3 \pm 1.48$ \\
$1 \cdot 10^{-7}$ & 88.7 & 2.1 & 18.5 & 22.8 & $5.9 \pm 0.70$ \\
$1 \cdot 10^{-8}$ & 91.2 & 1.4 & 16.5 & 20.3 & $5.1 \pm 0.62$ \\
\hline
\end{tabular}

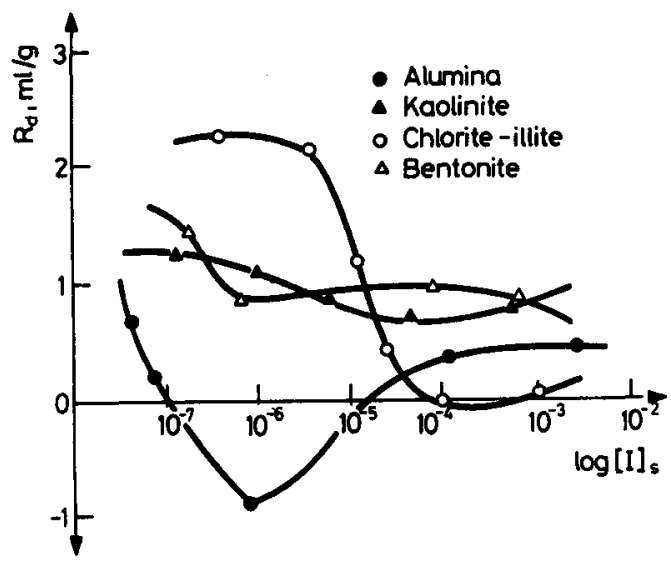

Fig. 5. Variation of the distribution ratio $R_{d}$ with $I^{-}$ion loading (concentration on solid phase) for: - alumina, $\Delta$ kaolinite, $O$ chlorite-illite, $\Delta$ bentonite

The percentages of adsorption, desorption and reversible sorption, are given in Table 3. Percent adsorption increases with decreasing initial iodine concentration in the solution.

In order to observe the extent of exchange of radioiodine in the solution with the inactive iodine bound to the sorption sites sorption experiments were performed with soil samples pretreated with $0.1 \mathrm{M}$ inactive NaI. The exchange reaction would be as follows:

$$
R \mathrm{I}+\mathrm{I}^{*} \Leftrightarrow R \mathrm{I}^{*}+\mathrm{I}^{-}
$$

The experimental results and exchange percentages are also given in Table 3. Higher exchange takes place at lower iodine concentrations $\left([]_{l}^{0} \leq 1 \cdot 10^{-6} \mathrm{M}\right)$ and the percent 
exchange values become close to the reversible sorption percentages at []$_{l}^{0} \leq 1 \cdot 10^{-7} \mathrm{M}$ iodine concentrations. This may be an indication of the fact that only iodine sorbed on the surfaces plays a role in desorption and exchange. BORS et al. ${ }^{5}$ have also found very low $R_{d}$ values (between 0.2 and $0.5 \mathrm{ml} / \mathrm{g}$ ) for exchange on two soil types and they state that not much exchange takes place between radioactive $\mathrm{I}^{-}$and inactive $\mathrm{I}^{-}$ion.

\section{Sorption isotherms}

The sorption and exchange data were fitted by Freundlich and DubininRadushkevich type isotherms. The Freundlich isotherm is perhaps the most widely used non-linear sorption equilibrium model. The isotherm has the general form of:

$$
X=K C^{N}
$$

where $\quad X$ - amount of solute adsorbed per unit mass of solid $(\mathrm{g} / \mathrm{g})$,

$C$ - equilibrium solute concentration of sorbate $(\mathrm{g} / \mathrm{ml})$,

$K, N$ - positive empirical parameters with $0<N<1$, ( $K$ is related to sorption capacity and $N$ to the sorption intensity).

A value of $N$ (Freundlich constant) less than one indicates the non-linearity of the isotherm.

The Dubinin-Radushkevich isotherm was developed to model adsorption of trace aqueous constituents and it is more general than the Langmuir isotherm since it does not require homogeneous adsorption sites or constant adsorption potential. The DubininRadushkevich isotherm is given as:

$$
X=X_{m} e^{-k E^{2}}
$$

where $\quad X-$ amount of solute absorbed per unit weight of solid $(\mathrm{mmol} / \mathrm{g})$,

$X_{m}$ - sorption capacity of adsorbent per unit weight $(\mathrm{mmol} / \mathrm{g})$,

$\varepsilon-$ Polanyi potential $=R T \ln (1+1 / C)(\mathrm{J} / \mathrm{mol})$,

$C$ - equilibrium solute concentration $(\mathrm{mmol} / \mathrm{ml})$,

$R$ - gas constant $(\mathrm{J} / \mathrm{K} \cdot \mathrm{mol})$,

$T$ - temperature (K),

$K$ - constant related to the sorption energy $\left(\mathrm{mol}^{2} / \mathrm{J}^{2}\right)$

The linearized form of Dubinin-Radushkevich equation is:

$$
\ln X=\ln X_{m}-K \varepsilon^{2}
$$


Table 4

Isotherm constants found from fits to Freundlich and Dubinin-Radushkevich type isotherms in the adsorption of jodine on organic rich soil and clay minerals

\begin{tabular}{lcccc}
\hline \multirow{2}{*}{$\begin{array}{c}\text { Solid } \\
\text { sample }\end{array}$} & \multicolumn{2}{c}{$\begin{array}{c}\text { Freundlich } \\
\text { isotherm }\end{array}$} & \multicolumn{2}{c}{$\begin{array}{c}\text { Dubinin-Radushkevich } \\
\text { isotherm }\end{array}$} \\
\cline { 2 - 5 } & $N$ & $K$ & $X_{m}$, meq/g & $K$ \\
\hline Soil (sorption) & 0.64 & 0.23 & $4.10 \cdot 10^{-3}$ & $3.71 \cdot 10^{-9}$ \\
Soil (exchange) & 0.86 & 0.48 & $1.63 \cdot 10^{-3}$ & $4.96 \cdot 10^{-9}$ \\
Chlorite-illite & 0.54 & 0.02 & $8.23 \cdot 10^{-4}$ & $3.17 \cdot 10^{-9}$ \\
Bentonite & 0.89 & 0.40 & $2.76 \cdot 10^{-3}$ & $5.15 \cdot 10^{-9}$ \\
Kaolinite & 0.77 & 0.31 & $4.09 \cdot 10^{-3}$ & $6.89 \cdot 10^{-9}$ \\
Alumina & 0.99 & 0.78 & $4.05 \cdot 10^{-3}$ & $4.32 \cdot 10^{-9}$ \\
\hline
\end{tabular}

Table 5

Adsorption energies calculated from the Dubinin-Radushkevich isotherm constant $K\left(E=(2 K)^{-1 / 2}\right)$ for organic rich soil and clay minerals

\begin{tabular}{lc}
\hline Solid matrix & $E, \mathrm{~kJ} / \mathrm{mol}$ \\
\hline Soil & 11 \\
Chlorite-illite & 11 \\
Bentonite & 10 \\
Kaolinite & 8.5 \\
Alumina & 11 \\
\hline
\end{tabular}

A plot of $\ln X$ versus $\varepsilon^{2}$, allows the estimation of $\ln X_{m}$ as the intercept and $-K$ as the slope. The value of $X_{m}$, the maximum adsorbed amount (sorption capacity), can be calculated from the intercept of this isotherm. The constants found from fitting the sorption and exchange data to these isotherms, are given in Table 4 for the sorption of iodine on organic rich soil and on clay minerals. Except for sorption on alumina, all $N$ values are well below 1.00 , indicating non-linear isotherms.

The mean energy of adsorption can be calculated from the Dubinin-Radushkevich isotherm. The mean energy of adsorption is defined as the free energy change when one mole of ion is transferred to the surface of the solid from infinity in the solution. It can be calculated from the equation: $E=(2 K)^{-1 / 2} \cdot{ }^{12}$ The results for organic rich soil and clay minerals are given in Table 5. All values are in the energy range for ion-exchange type reactions $(8-16 \mathrm{~kJ} / \mathrm{mol})$. No previous data are available in the literature for the adsorption energy estimation of radioiodine for comparison. 


\section{S. ASSEMI, H. N. ERTEN: SORPTION OF RADIOIODINE}

SPOSITO ${ }^{13}$ has used the empirical Freundlich constants to obtain information about the heterogeneity of the adsorbing sites, for a binary exchange reaction, where one of the species is adsorbed in trace amounts. He has assumed that the adsorption sites may be grouped into classes, each characterized by the number of sites it contains and by the relative affinity it possesses for the exchanging species. The exchange reaction in each class of sites is described by the Langmuir equation. The site distribution function is defined as:

$$
m(q)=m_{\max } \frac{2 \cos (\pi N) \exp \left[N\left(q_{m}-q\right)\right]}{1+2 \cos (\pi N) \exp \left[N\left(q_{m}-q\right)\right]+\exp \left[2 N\left(q_{m}-q\right)\right]}
$$

where

$$
\begin{aligned}
m(q) & \text { - number of sites of class } \mathrm{q}, \\
q & \text { - class of adsorption sites, } \\
m_{\max } & \text { - value of } m(q) \text { at its maximum, } \\
q_{m} & \text { - value of } q \text { when } m_{q}=m_{\max }, \\
N & \text { - Freundlich exponent, }
\end{aligned}
$$

$q$ is related to the affinity parameters of species A and B and it is defined as:

$$
q \equiv \ln \left(K_{\mathrm{A}} / K_{\mathrm{B}}\right)
$$

$m_{\max }$ is calculated from the equation:

$$
m_{\max }=\frac{M}{2 \pi} \tan (\pi N / 2)
$$

where $M$ is the total number of adsorption sites. The value of $q_{m}$ is calculated from the following equation:

$$
q_{m}=(1 / N) \ln \alpha
$$

The parameter $\alpha$ is calculated from:

$$
\alpha=K c_{B}^{N} / M
$$

$K$ and $N$ are the Freundlich constants and $c_{B}$ is the average concentration of species $B$ in the solution. For the adsorption of radioiodine on soil and clay minerals, the competing ion was taken as $\mathrm{Cl}^{-}$, since its size and charge are close to those of iodide and both are in the same group. The results of site distribution calculations for soil and clay minerals are given in Table 6 and are shown in Fig. 6 . All sites were found to have a greater affinity for $\mathrm{Cl}^{-}$ion as compared to $\mathrm{I}^{-}$ion. The reason may be the smaller size 


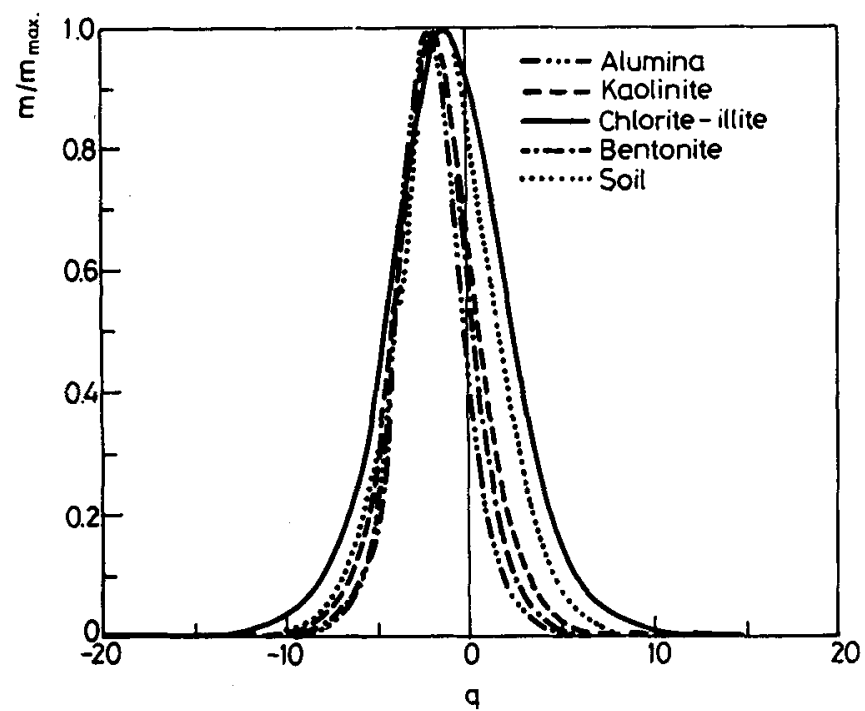

Fig. 6. Site distribution curve for the adsorption of radioiodine on organic rich soil and on clay minerals with $\mathrm{Cl}^{-}$as the competing ion; - . . - alumina, $-\ldots$ kaolinite, chlorite-illite, - - bentonite, ...... soil

Table 6

Parameters used to calculate the site distribution functions of clay minerals and the affinity ratios found for the adsorption of iodine on organic rich soil and clay minerals

\begin{tabular}{lccc}
\hline Solid matrix & $\alpha$ & $q_{\max }$ & $\begin{array}{c}\text { Affinity ratio, } \\
K_{\mathrm{Cr}} / K_{\mathrm{I}-}\end{array}$ \\
\hline Soil & 0.46 & -1.20 & 3.32 \\
Chlorite-illite & 0.52 & -1.21 & 3.36 \\
Bentonite & 0.20 & -1.83 & 6.24 \\
Kaolinite & 0.24 & -1.85 & 6.35 \\
Alumina & 0.13 & -2.10 & 7.97 \\
\hline
\end{tabular}

of $\mathrm{Cl}^{-}$. There are, however, a smaller number of sites (positive region of the curves) that have a higher affinity for $\mathrm{I}^{-}$. The organic rich soil and chlorite-illite clay were found to have the highest affinity for $\mathrm{I}^{-}$ion as compared to other clay minerals. 


\section{References}

1. B. ALLARD, KBS-TR 82-81, Swedish Nuclear Fuel Supply Co. (SKBF), Stockholm, Sweden, 1982.

2. Final Storage of Spent Nuclear Fuel-KSB-3, Swedish Nuclear Fuel Supply Co. (SKBF)-KBS Vol. I, Stockholm, Sweden, 1983.

3. D. C. WHITEHEAD, J. Appl. Ecol., 16 (1979) 269.

4. H. N. ERTEN, S. AKSOYOĞLU, H. GÖKTÜRK, Sci. Total Env., 69 (1988) 269.

5. J. BORS, H. N. ERTEN, R. MARTENS, Radiochim. Acta, 52/53 (1991) 317.

6. Y. LIU, H. VON GUNTEN, Migration Chemistry and Behavior of Iodine Relevant to Geological Disposal of Radioactive Wastes, PSI-Bericht Nr. 16, 1988.

7. K. B. KRAUSKOPF, Introduction to Geochemistry, 2nd ed., McGraw Hill, 1979.

8. M. I. SHEPPARD, D. H. THAIBAULT, Health Phys., 59, No. 4 (1990) 471.

9. G. M. MILTON, R. J. CORNETT, S. J. KRAMER, A.. VEZINA, the Transfer of lodine and Technetium Tracers From Surface Waters to Sediments, Migration-92, Jerez, Spain, 1992.

10. J. M. WEST, N. CHRISTOFI, J. C. PHILIP, S. C. ARME, Investigations on the Populations of Introduced and Resident Micro-Organisms in Deep Repositories and Their Effects on Containment of Radioactive Wastes, CEC Report, EUR 10405 EN, 1986.

11. S. STRACKA, A. MULLER, Studies of the Microbiological Influence on the Behavior of lodine-125 in Humus Soil, Proc. CEC Workshop Held in Brussels, 1984.

12. L. L. AMES, J. E. McGRARRAH, B. A. WALKER, P. F. SALTER, Chem. Geol., 35 (1982) 205.

13. G. SPOSITO, Soil Sci. Soc. Am. J., 44 (1980) 652. 